\title{
Real World Experience of Long Term Treatment Outcome in Hormone Receptor-positive Metastatic Breast Cancer with or without Everolimus and Exemestane after Prior Aromatase Inhibitor
}

\author{
Thanate Dajsakdipon ${ }^{1}$, Jitprapa Konmun², Umaporn Udomsubpayakul ${ }^{3}$, Thitiya \\ Dejthevaporn ${ }^{1}$
}

${ }^{1}$ Division of Oncology, Department of Medicine, Faculty of Medicine Ramathibodi Hospital, Mahidol University, Bangkok, Thailand. ${ }^{2}$ Department of pharmacy, Faculty of Medicine Ramathibodi Hospital, Mahidol University, Bangkok, Thailand. ${ }^{3}$ Section for Clinical Epidemiology and Biostatistics, Faculty of Medicine Ramathibodi Hospital, Mahidol University, Bangkok, Thailand.

\begin{abstract}
Background: Everolimus/exemestane has been shown to improve progression-free survival in patients with endocrine-resistant metastatic breast cancer. The regimen has been well-accepted despite lack of survival benefit. In real-life setting, patients were not well-selected and hence benefit of such treatment may not be as robust. Method: This is a retrospective review of 143 hormone receptor (HR) positive, HER-2 negative MBC patients who progressed on nonsteroidal aromatase inhibitors. Patients who received everolimus/exemestane in any treatment lines (EE group) were compared to patients who never received everolimus (NE group). Primary end point was survival adjusted to prognostic factors. Results: There were 52 patients in EE group and 91 in NE group with mean age of 58.6 years. Median follow-up time was 51 months. Unadjusted median OS was significantly longer in EE [33 vs 25 months, HR 0.66 (95\%CI 0.44-0.998); $p=0.049$ ]. In univariate analysis, factors affecting survival included numbers of metastatic sites, bone metastasis, EE treatment and numbers of treatment lines. Independent factors that remained significant in multivariate analysis were treatment lines [HR $0.71(95 \%$ CI $0.63-0.79) ; p<0.05]$ and numbers of metastatic sites. Median numbers of treatment line after NSAI failure was 5.2 vs 3.6 lines in EE and NE, respectively. Conclusion: In this real-life practice data, pts with HR positive, HER-2 negative MBC who had progressed on NSAI, sequential use of multiple treatment regimens of endocrine and chemotherapy is essential to longer survival. Everolimus/exemestane may have contributed, to a lesser extent, to this improvement in survival.
\end{abstract}

Keywords: Breast cancer- endocrine resistance- endocrine refractory- everolimus- metastatic breast cancer

\section{Introduction}

Breast cancer is the most common female cancer in Thailand [1] and consisted of many different subtypes such as hormone receptor (HR) positive, amplified-human epidermal growth factor receptor type 2 (HER-2), or triple negative breast cancer.(2) Over two-thirds of breast cancer patients are HR positive disease [3]. Metastatic breast cancer (MBC) is so far incurable. The goal of treatment at this stage is to control tumor growth, improve quality of life and prolong survival [4]. The treatment strategies of HR positive and HER-2 non-amplified MBC included endocrine and chemotherapy [2,5]. Patient with asymptomatic, mildly symptomatic or non-visceral crisis may be treated upfront by endocrine therapy which carries less side effects and provides better quality of life compared to chemotherapy-based therapy [6-7]. Multiple classes of endocrine therapy agents are available, included selective estrogen receptor modulator (SERM) such as

Corresponding Author:

Dr. Thitiya Dejthevaporn

Division of Oncology, Department of Medicine, Faculty of Medicine Ramathibodi Hospital, Mahidol University, Bangkok, Thailand.

Email: tsirisinha@yahoo.com 
tamoxifen, selective estrogen receptor down regulator (SERD) such as fulvestrant, non-steroidal aromatase inhibitor (AI) (anastrozole and letrozole) and steroidal AI (exemestane) [2]. In postmenopausal women, AI are more effective than tamoxifen [8-11], while non-steroidal AI (NSAI) are equally effective to steroidal AI [12-13]. More recently, CDK4/6 inhibitors have emerged as a highly effective treatment option in combination with the aforementioned agents [14-19]. Sequential use of these agents provides meaningful disease control period before chemotherapy initiation [20-23].

Everolimus is a sirolimus derivative that inhibits mTOR through allosteric binding to mTOR complex 1 [24]. Activation of phosphatidylinositol-3-kinase (PI3K)-protein kinase B (AKT)-mammalian Target of Rapamycin (mTOR) pathways has been proposed as one mechanism of endocrine resistance [25-28], in which everolimus has been shown to reverse such occurrence. The drug has been approved for advance ER positive, HER2 negative breast cancer that has progressed on NSAI in several countries worldwide including Thailand since 2013. The approval was based on the positive results from 2 randomized control trials, a phase 2 TAMRAD study [29] and phase 3 BOLERO-2 trial [30-33]. Both studies showed a remarkable improvement in progression free survival (PFS) with HR of 0.54 and 0.45 , respectively. However, upon longer follow-up, a survival benefit could not be demonstrated so far [32]. In addition, in a more recent phase 2 trial, BOLERO-6 study [34], the effectiveness of this combination compared to capecitabine, a commonly used single agent chemotherapy in $\mathrm{MBC}$ remained inconclusive.

Due to CDK4/6 inhibitors is a novel and expensive drug in Thailand which only few people who can access it. And CDK4/6 inhibitor has just been launched in Thailand since middle year of 2018 while PI3K inhibitors is likely to be launched in late 2020, therefore data of CDK4/6 inhibitor including PI3K inhibitors in a real-world practice especially low to middle income regions like in Thailand is very limited. Compare to CDK4/6 inhibitors and PI3K inhibitors, everolimus is more widely accessible in Thailand.

Due to the high cost of everolimus in Thailand together with its toxicity, notwithstanding the lack of survival advantage, called for a cautious use of the agent. In spite of the fact that the population in BOLERO-2 trial were not heavily pretreated, in real life practice in Thailand, this was not a common practice pattern and many patients had received several lines of systemic therapy before being treated with everolimus-exemestane combination in later lines. There has been limited data on its efficacy and optimal timing in routine clinical practice in Thai patients. So, this study was conducted to evaluate the efficacy of combination of everolimus and exemestane in a broader population i.e. in any line of treatment compared with everolimus-free regimen using survival as a primary endpoint in HR positive, HER-2 negative MBC that had progressed on previous NSAI in a single academic center.

\section{Materials and Methods}

\section{Patients}

Patients were eligible to be included in the study if they were postmenopausal with histological or cytological confirmation of HR positive and HER-2 nonamplified MBC without visceral crisis, whose disease was refractory to previous letrozole or anastrozole therapy. NSAI-refractory was defined as recurrence while on, or within 12 months of adjuvant therapy with letrozole or anastrozole, or progression during treatment, or within one month of treatment with NSAI for locally advanced or MBC. Other previous anticancer endocrine treatments and/or chemotherapy regimen for metastatic disease were allowed. Exclusion criteria were age of 17 years or younger, use of mTOR inhibitor prior to NSAI, lack of detailed clinical data and HER2 amplified MBC. All patients were diagnosed with NSAI resistance during January 1, 2013 to August 31, 2017 and received treatment at Ramathibodi hospital, a tertiary care, referral hospital in Bangkok, Thailand.

\section{Study Design and Treatment}

We retrospectively collected data of NSAI refractory MBC patients from Ramathibodi Cancer Registry from January 1, 2013 to August 31, 2017. All patients who were diagnosed with NSAI refractory were categorized according to the subsequent treatment they received into 2 groups: 1) patients who received everolimus and exemestane combination in any line were defined as everolimus-exemestane (EE) group and 2) those who had never been treated with everolimus in any line of treatment [defined as non-everolimus (NE) group]. Treatment assignments were based on treating physicians' decision.

The primary end point of the study was overall survival (OS), defined as time at NSAI refractory to death from any causes. Secondary end points included OS in subgroup of patients treated with EE in various sequence, i.e., immediately or subsequently after NSAI failure; progression-free survival (PFS) and response rate of EE combination therapy compared with others systemic therapy as first subsequent line of treatment after NSAI failure. PFS was defined by time at start of treatment to time of progression on the basis of radiographic study assessed by investigators or death. The study was approved by institutional review board of Faculty of Medicine Ramathibodi Hospital, Mahidol University, Bangkok, Thailand.

\section{Statistical Analyses}

OS and PFS were estimated with the use of the Kaplan-Meier method and comparison between groups, using log rank test. A cox-proportional hazard model was used to estimate the hazard ratios (HR). Patient's baseline characteristics were reported using descriptive statistics. All qualitative variables were compared with the chi-square test or Fisher's test. All quantitative variables were compared with the student's t-test. Univariate and multivariate cox regression analysis were used to analyze prognostic factors affecting survival of endocrine 
refractory, HER-2 negative MBC patients. A p-value of $<0.05$ was considered to be statistically significant. All analyses were performed with the use STATA, version 15 .

\section{Results}

Patient Characteristics

A total of 143 women who fulfilled the eligibility criteria were identified from Ramathibodi Cancer Registry database between January 1, 2013 and August 31, 2017. There were 52 patients in EE group and 91 patients in the NE group. Baseline characteristics were summarized in
Table 1 . The mean age in both groups was 58 years. Nearly all of them had Eastern Cooperative Oncology Group (ECOG) score of 0 to 1 . There were numerically higher numbers of metastatic sites and visceral metastasis in $\mathrm{EE}$ group without statistical difference. Twenty-three percent each had tumor progression while on adjuvant endocrine therapy. NSAI was the first line treatment of MBC in $67.3 \%$ in EE group and $58 \%$ in NE group $(\mathrm{p}=0.56)$. No significant difference in numbers of systemic therapy (chemotherapy / endocrine therapy) received prior to NSAI were seen. Approximately one-third in both arms had received chemotherapy in metastatic setting before

Table 1. Baseline Characteristics

\begin{tabular}{|c|c|c|c|}
\hline Characteristic & $\begin{array}{l}\text { Everolimus-exemestane } \\
\qquad(\mathrm{N}=52)\end{array}$ & $\begin{array}{l}\text { Non-everolimus } \\
\qquad(\mathrm{N}=91)\end{array}$ & p-value \\
\hline Age of endocrine refractory & & & 0.81 \\
\hline Year, mean + SD & $58.3+11.3$ & $58.8+11.7$ & \\
\hline ECOG & & & 0.86 \\
\hline 0 & $9(17.3 \%)$ & $17(18.7 \%)$ & \\
\hline 1 & $37(71.1 \%)$ & $66(72.5 \%)$ & \\
\hline 2 or more & $6(11.5 \%)$ & $8(8.8 \%)$ & \\
\hline No. of metastatic site(s) & & & 0.28 \\
\hline 1 & $15(28.8 \%)$ & $38(41.8 \%)$ & \\
\hline 2 & $22(42.3 \%)$ & $34(37.4 \%)$ & \\
\hline 3 or more & $15(28.8 \%)$ & $19(20.9 \%)$ & \\
\hline Visceral metastasis (lung or liver or pleural or lymphangitis) & $41(78.8 \%)$ & $61(67.4 \%)$ & 0.13 \\
\hline \multicolumn{4}{|l|}{ Metastatic site } \\
\hline Lung & $25(48.1 \%)$ & $39(42.9 \%)$ & 0.55 \\
\hline Liver & $21(40.4 \%)$ & $25(27.5 \%)$ & 0.11 \\
\hline Bone & $36(69.2 \%)$ & $55(60.4 \%)$ & 0.29 \\
\hline Brain & $2(3.8 \%)$ & $7(7.7 \%)$ & 0.49 \\
\hline Bone only disease & $7(13.5 \%)$ & $19(20.9 \%)$ & 0.27 \\
\hline Previous endocrine treatment for metastasis before NSAI & & & 0.84 \\
\hline Tamoxifen & $7(13.5 \%)$ & $15(16.5 \%)$ & \\
\hline Others & $1(1.9 \%)$ & $2(2.2 \%)$ & \\
\hline No & $44(84.6 \%)$ & $74(81.3 \%)$ & \\
\hline \multicolumn{4}{|l|}{ Previous treatment with letrozole or anastrozole } \\
\hline Adjuvant therapy only $\dagger$ & $12(23.1 \%)$ & $21(23.1 \%)$ & 0.88 \\
\hline Metastatic disease (with or without adjuvant NSAI) & $40(76.9 \%)$ & $70(76.9 \%)$ & $>0.05$ \\
\hline \multicolumn{4}{|l|}{ Previous chemotherapy } \\
\hline Neoadjuvant or adjuvant therapy only & $28(58.3 \%)$ & $42(47.7 \%)$ & 0.24 \\
\hline $\begin{array}{l}\text { Treatment of metastatic disease (with or without prior } \\
\text { neoadjuvant or adjuvant chemotherapy) }\end{array}$ & $17(32.7 \%)$ & $29(31.9 \%)$ & 0.92 \\
\hline No. of lines of chemotherapy for metastatic disease before NSAI & $(\mathrm{N}=17)$ & $(\mathrm{N}=29)$ & \\
\hline 1 & $12(70.6 \%)$ & $14(48.3 \%)$ & \\
\hline 2 & $4(23.5 \%)$ & $13(44.8 \%)$ & \\
\hline 3 & $1(5.9 \%)$ & $2(6.9 \%)$ & \\
\hline No. of previous systemic therapy before NSAI in metastatic setting & & & 0.56 \\
\hline 0\# & $35(67.3 \%)$ & $53(58.2 \%)$ & \\
\hline 1 & $9(17.3 \%)$ & $21(23.1 \%)$ & \\
\hline 2 or more & $8(15.4 \%)$ & $17(18.7 \%)$ & \\
\hline
\end{tabular}

$\uparrow$ Number of patients who progressed on adjuvant letrozole or anastrozole; \# 0, patients who received NSAI as first-line treatment of MBC 


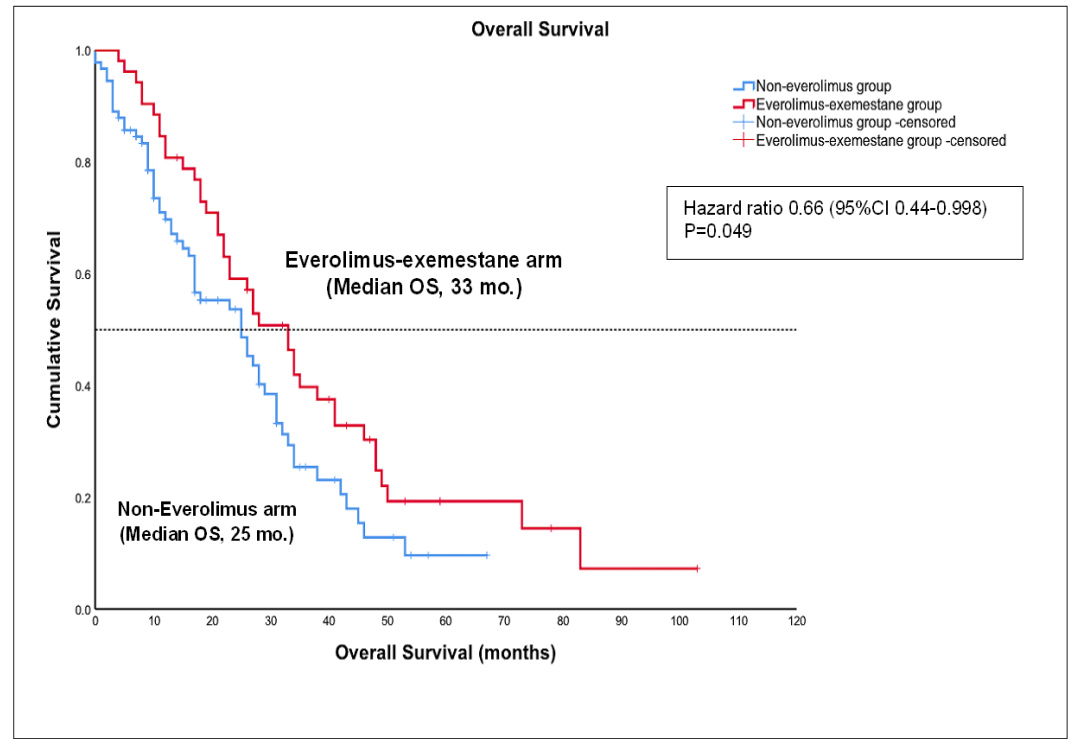

Figure 1. Kaplan-Meier Plot of Overall Survival; OS denotes overall survival

NSAI and most had received less than 3 chemotherapy regimens prior to NSAI. For patients in EE group $(\mathrm{n}=52)$, 13 patients $(25 \%)$ and 39 patients $(75 \%)$, the starting dose of everolimus was $5 \mathrm{mg}$ per day and $10 \mathrm{mg}$ per day, respectively. Of those who received $10 \mathrm{mg}$ daily dose, $44 \%$ of them required a dose reduction during treatment.

\section{Efficacy End Points}

Data was censored on 31 August 2018, with median follow-up time of 51 months (59 months in EE and 36 months in NE). Among 143 patients, 100 patients had died (70\%) (EE: 40 patients, NE: 60 patients). Median OS of $\mathrm{EE}$ and NE group were 33 and 25 months, respectively. (HR of death, 0.66 ; 95\% confidence interval (CI) $0.44-$ 0.998; $p=0.049$ ) (Figure 1, Table 2).

Of 52 patients in EE group, 14 patients (27\%) received everolimus as first subsequent treatment following NSAI failure, while 18 patients (35\%) and 20 patients $(38 \%)$ received everolimus as a second and later line following progression on NSAI. Median numbers of prior chemotherapy and endocrine therapy before receiving EE was 3 lines (range 1-7), i.e. EE was given as $4^{\text {th }}$ line of treatment. In both groups, the 4 most commonly used agents after NSAI failure (aside from everolimus in EE group) were capecitabine, paclitaxel, fulvestrant and exemestane, with no difference in frequency between the 2 groups (Table 3 ). However, significantly more patients in EE group received eribulin ( $44 \%$ vs $20 \%, \mathrm{p}=0.002)$. Patients in EE group received more lines of systemic treatment in metastatic setting after NSAI refractory with mean $(+2 \mathrm{SD})$ of $5.19(+2.51)$ lines compared to 3.62 $(+2.19)$ lines in NE group $(p<0.05)$. Due to the imbalance in the total treatment received between the 2 groups, this factor was incorporated into factor analysis for survival together with other baseline variables known to be prognostic. A univariate analysis for prognostic factors to survival (Table 4) indicated EE treatment, number of metastatic sites, bone metastasis and number of total lines of treatment after NSAI refractory were significant factors. In multivariate analysis (Table 4), 2 factors that remained as independent factors for survival were number of total lines of treatment after NSAI refractory [HR per one line increase 0.71 (95\% CI0.64-0.79); $\mathrm{p}<0.05$ ], and numbers of metastatic site [HR per one site increase 1.35 (95\%CI 1.05-1.73); $p=0.02]$. Treatment with everolimus-exemestane was no longer significant in multivariate analysis [HR $0.74(0.48-1.14) ; \mathrm{p}=0.17$ ].

Subgroup analysis of survival showed benefits in all subgroups of patients who received EE except for patients who have had chemotherapy before NSAI and those who were heavily pretreated with chemotherapy. However, the confidence intervals were very wide (Figure 2).

Table 2. Efficacy Analysis

\begin{tabular}{lcccc}
\hline Variable & $\begin{array}{c}\text { Everolimus+exemestane } \\
(\mathrm{n}=52)\end{array}$ & $\begin{array}{c}\text { Non-everolimus } \\
(\mathrm{n}=91)\end{array}$ & p-value & Hazard ratio (95\%CI) \\
\hline Overall survival & $40(76.9)$ & $60(65.9)$ & 0.04 & $0.66(0.44-0.998)$ \\
Event-Death, & & & \\
No (\%) & $33(18-48)$ & $25(10-38)$ & & \\
Duration, months (Median, IQR $\dagger)$ & $25.67-40.33$ & $16.26-33.74$ & \\
$95 \% \mathrm{CI}$ &
\end{tabular}

CI denotes confidence interval; $\uparrow$ IQR denotes interquartile range 
Table 3. Systemic Treatment after NSAI Refractory

\begin{tabular}{lccc}
\hline & Everolimus-Exemestane Arm $(\mathrm{n}=52)$ & Non-Everolimus Arm $(\mathrm{n}=91)$ & $\mathrm{p}$-value \\
\hline Paclitaxel & $35(67.3 \%)$ & $49(53.8 \%)$ & 0.12 \\
Capecitabine & $34(65.4 \%)$ & $52(57.1 \%)$ & 0.33 \\
Fulvestrant & $30(57.7 \%)$ & $45(49.5 \%)$ & 0.34 \\
Eribulin & $23(44.2 \%)$ & $18(19.8 \%)$ & $0.002^{* *}$ \\
Exemestane & $17(32.7 \%)$ & $37(40.7 \%)$ & 0.34 \\
Docetaxel & $17(32.7 \%)$ & $23(25.3 \%)$ & 0.34 \\
Tamoxifen & $14(26.9 \%)$ & $29(31.9 \%)$ & 0.54 \\
AC & $6(11.5 \%)$ & $9(9.9 \%)$ & 0.76 \\
Megestrol & $5(9.6 \%)$ & $14(15.4 \%)$ & 0.33 \\
Gemcitabine & $4(7.7 \%)$ & $9(9.9 \%)$ & 0.66 \\
Nab-Paclitaxel & $1(1.9 \%)$ & $1(1.1 \%)$ & $>0.05$ \\
Ixabepilone & $1(1.9 \%)$ & 0 & 0.36 \\
Lipo-doxorubicin & $1(1.9 \%)$ & $1(1.1 \%)$ & $>0.05$ \\
Vinorelbine & $1(1.9 \%)$ & $3(3.3 \%)$ & $>0.05$ \\
CMF & 0 & $2(2.2 \%)$ & 0.53 \\
Cyclophosphamide & 0 & $1(1.1 \%)$ & $>0.05$ \\
\hline
\end{tabular}

$\overline{\mathrm{p}}<0.05$ indicates statistically significant; AC denotes anthracycline-cyclophosphamide; CMF denotes cyclophosphamide-methotrexate fluorouracil

Table 4. Univariate and Multivariate Analysis of Prognostic Factor for Overall Survival in ER Positive, HER-2 Negative Metastatic Breast Cancer Patients

\begin{tabular}{|c|c|c|c|c|}
\hline \multirow[t]{2}{*}{ Factors } & \multicolumn{2}{|c|}{ Univariate analysis } & \multicolumn{2}{|c|}{ Multivariate analysis } \\
\hline & $\begin{array}{l}\text { Hazard Ratio } \\
(95 \% \mathrm{CI})\end{array}$ & P-value & $\begin{array}{l}\text { Hazard Ratio } \\
\qquad(95 \% \mathrm{CI})\end{array}$ & p-value \\
\hline Everolimus-exemestane treatment & $0.66(0.437-0.998)$ & $0.049 * *$ & $0.74(0.48-1.14)$ & 0.17 \\
\hline Age of endocrine refractory (per 1 year) & $1.00(0.98-1.02)$ & 0.959 & & \\
\hline ECOG (per one ECOG status) & $1.31(0.92-1.86)$ & 0.14 & & \\
\hline Number of metastatic sites & $1.28(1.02-1.61)$ & $0.03 * *$ & $1.35(1.05-1.73)$ & $0.02 * *$ \\
\hline Visceral (lung or liver or pleural or lymphangitis) metastasis & $1.08(0.69-1.696)$ & 0.74 & & \\
\hline \multicolumn{5}{|l|}{ Metastatic site } \\
\hline Lung & $0.67(0.45-1.01)$ & 0.06 & & \\
\hline Liver & $1.45(0.96-2.19)$ & 0.08 & & \\
\hline Bone & $1.61(1.05-2.47)$ & $0.03 * *$ & $1.34(0.86-2.1)$ & 0.19 \\
\hline Brain & $0.96(0.39-2.36)$ & 0.93 & & \\
\hline Bone only disease & $0.93(0.55-1.59)$ & 0.8 & & \\
\hline \multicolumn{5}{|l|}{ Previous endocrine treatment for metastasis before NSAI (compared to without) } \\
\hline Tamoxifen & $1.24(0.7-2.196)$ & 0.45 & & \\
\hline Others & $0.63(0.15-2.56)$ & 0.52 & & \\
\hline \multicolumn{5}{|l|}{ Previous treatment with letrozole or anastrozole } \\
\hline Progressed on Adjuvant therapy & $0.77(0.48-1.24)$ & 0.29 & & \\
\hline Metastatic disease (with or without adjuvant NSAI) & $1.29(0.8-2.08)$ & 0.295 & & \\
\hline \multicolumn{5}{|l|}{ Previous chemotherapy } \\
\hline Neoadjuvant or adjuvant therapy & $1.05(0.695-1.58)$ & 0.83 & & \\
\hline Neoadjuvant or adjuvant therapy & $0.9(0.59-1.39)$ & 0.65 & & \\
\hline \multicolumn{5}{|l|}{ for metastatic disease } \\
\hline No. of previous systemic therapy prior to refractory to NSAI (per one line) & $1.04(0.83-1.29)$ & 0.75 & & \\
\hline No. of lines treatment after NSAI refractory (per one line) & $0.71(0.64-0.79)$ & $<0.05 * *$ & $0.71(0.63-0.79)$ & $<0.05 * *$ \\
\hline
\end{tabular}

CI denotes confident interval; $* * \mathrm{P}<0.05$ indicates statistically significant 


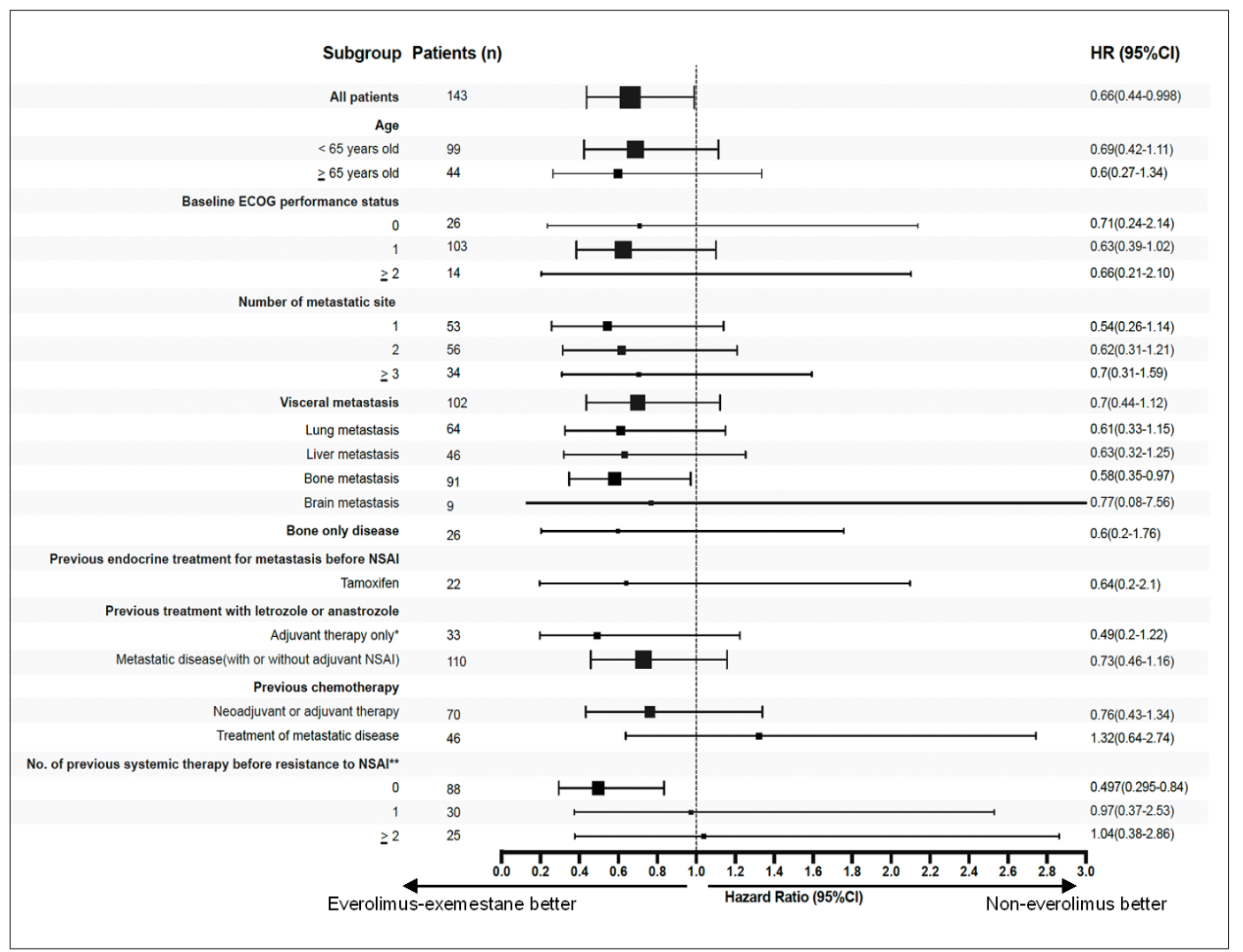

Figure 2. Overall Survival in the Various Subgroups; *Patients who progressed on adjuvant NSAI. **Number of previous systemic therapy before refractory to NSAI in metastatic setting, 0 indicating that the patient progressed on or within a year of end of adjuvant endocrine therapy or on first line treatment with NSAI, 1 indicating that progressed on second line NSAI, $>2$ indicating that progressed on third or later lines of NSAI. The size of each square is proportional to the number of patients in the subgroup. The data are shown on a semi-logarithmic scale

\section{Timing of Everolimus and Outcome}

Median OS in patients treated with EE as first, second and third subsequent line after refractory to NSAI were 23, 21 and 38 months, respectively (Table 5). The corresponding OS in NE group was 25 months. Comparison between groups with different timing of treatment and control revealed a non-significant difference in OS (log-rank p 0.16). HR of death in patients treated with EE in first, second and third/ subsequent line after refractory to NSAI were not statistically different (HR $0.91,0.74$ and $0.499 ; \mathrm{p}=0.16$ by log rank test) (Table 5).

Within the EE group, there were 32 patients $(62 \%)$ who had received $<1$ line of chemotherapy before EE, which was one of the inclusion criteria of BOLERO-2 trial [30]. OS of this subgroup was 28 months (16.35-39.65) (Table 6).

Median duration of treatment with EE was 4 months (95\% CI 2.2-5.8), time on treatment was noted to be longer with earlier use of EE (Table 5).

Progression-Free Survival and Response Rate after AI Failure

Overall PFS of the entire EE group was 8 months (95\% CI 5.3-10.7). In order to evaluate anti-tumor activity of EE, we explored the PFS of patients treated with EE immediately after NSAI $(n=14)$ compared to those treated with other agents listed in Table 7. Early use of EE gave a superior trend in median PFS of 10 months, whereas with the commonly used single agent chemotherapy or non-everolimus-based endocrine therapy, PFS ranged from 4-7 months. Fulvestrant seemed to provide the longest PFS among others.

Objective responses, on the basis of radiographic studies assessed by local investigators, in first subsequent treatment after NSAI refractory with EE and other agents were summarized in Table 8 . There was no complete response (CR) except for one unconfirmed CR with tamoxifen. The overall clinical benefit response $(\mathrm{CR}+\mathrm{PR}+\mathrm{SD})$ was numerically higher in patients received EE, paclitaxel and docetaxel, as compared to others.

\section{Discussion}

We described a retrospective cohort study of patients with advanced ER positive breast cancer after failure from NSAI whose subsequent therapy contained or devoided of everolimus-exemestane in a real-life practice. As of this study, CDK4 / 6 inhibitors and PI3K inhibitors were not included due to a financial incompatibility and an inaccessibility of these drugs in Thailand. Patients in both comparison groups were well-balanced in baseline characteristics including prior therapy before NSAI. Our study explored the use of EE in a much broader population than in the pivotal BOLERO-2 study, which 
Table 5. Overall Survival of Everolimus-Exemestane according to Lines of Treatment after NSAI Refractory

\begin{tabular}{lccc}
\hline & $\begin{array}{c}\text { Median Duration of Treatment } \\
\text { with EE (95\%CI), months }\end{array}$ & $\begin{array}{c}\text { Median Overall } \\
\text { Survival (95\%CI), months }\end{array}$ & $\begin{array}{c}\text { Hazard } \\
\text { Ratio of Death } \dagger\end{array}$ \\
\hline First line $(\mathrm{n}=14)$ & $9(6.6-11.4)$ & $23(17.2-28.8)$ & 0.91 \\
becond line $(\mathrm{n}=18)$ & $4(2.6-5.4)$ & $21(15.8-26.2)$ & 0.74 \\
Later line $(\mathrm{n}=20)$ & $3(1.6-4.4)$ & $38(29.3-46.8)$ & 0.499 \\
Non-everolimus group $(\mathrm{n}=91)$ & & $25(16.3-33.7)$ & \\
\hline
\end{tabular}

$\dagger$ Hazard ratio of death of $1^{\text {st }}, 2^{\text {nd }}$, Later line of treatment compared with non-everolimus group; $p<0.05$ indicates statistically significant; CI denotes confidence interval

Table 6. Overall Survival in Patients Receiving $<1$ Line of Chemotherapy Before Everolimus

\begin{tabular}{lllr}
\hline & EE group $(\mathrm{n}=32)$ & NE group $(\mathrm{n}=91)$ & Hazard ratio $(95 \% \mathrm{CI}), \mathrm{p}$-value \\
\hline Median OS (months) $(95 \% \mathrm{CI})$ & $28(16.35-39.65)$ & $25(16.26-33.74)$ & $0.7(0.43-1.14), \mathrm{p}=1.56$ \\
\hline $\begin{array}{l}\text { EE denotes everolimus-exemestane, NE denotes non-everolimus; PFS denotes progression free survival, OS denotes overall survival, CI denotes } \\
\text { confidence interval }\end{array}$
\end{tabular}

Table 7. Progression-Free Survival of First Subsequent Treatment after NSAI Failure Using Various Agents

\begin{tabular}{lccccc}
\hline & Number of patients & Median PFS (months) & $95 \%$ CI & $\begin{array}{c}\text { HR of EE compared } \\
\text { with other agents }\end{array}$ & p-value \\
\hline Everolimus-exemestane & 14 & 10 & $8.5-11.6$ & & 0.84 \\
Capecitabine & 12 & 4 & $0-9.97$ & 0.84 & 0.72 \\
Exemestane & 17 & 4 & $2.7-5.3$ & 0.88 & 0.66 \\
Fulvestrant & 30 & 7 & $3.1-10.9$ & 0.52 & 0.74 \\
Tamoxifen & 11 & 6 & $3.9-8.1$ & 0.43 & 0.16 \\
Paclitaxel & 30 & 5 & $4.4-5.6$ & 1.07 & 0.11 \\
Docetaxel & 13 & 6 & $4.1-7.9$ & 0.91 \\
\hline
\end{tabular}

PFS denotes progression free survival, HR denotes hazard ratio, CI denotes confidence interval; $\mathrm{p}<0.05$ indicates statistically significant

is much more representative of the real-world situation. The result showed that the use of everolimus-exemestane combination, although exerted some therapeutic benefit, did not translate to overall survival when adjusted for an imbalance in subsequent therapy. The more important factor for survival of these patients in our study was the ability to receive as many lines of treatment as possible. This finding, in fact, is in line with the final analysis of survival in BOLERO-2.

In this study, we chose overall survival as a primary endpoint as it is a more solid outcome than progression-free survival in retrospective database. To our knowledge, it is the study with the second longest follow-up time next to Italian cohort [35]. The median follow-up time was 51 months compared to 29 months in BOLERO-2 and 5 to 67 months in other phase IIIb expanded studies [32, 35-39] Hence, we are confident that the result represented a reasonably mature outcome. In addition, none of those expanded access reports and other real-world setting retrospective data have focused on overall survival; they mainly explored the response and safety aspects of EE.

Patients in our study, in some aspects, were different from BOLERO-2. They carried more visceral metastasis (79\% vs 56\%) and more liver metastasis (40\% vs $33 \%)$. Despite high numbers of visceral metastasis, $58-67 \%$ of our patients received NSAI as their first

Table 8. Response Rate to First Subsequent Treatment after NSAI Failure Using Various Agents

\begin{tabular}{lccccccc}
\hline & EE & Capecitabine & Exemestane & Fulvestrant & Tamoxifen & Paclitaxel & Docetaxel \\
\hline Number (total) & 14 & 12 & 18 & 32 & 12 & 32 & 13 \\
$\mathrm{CR}$ & 0 & 0 & 0 & 0 & $1(8.3 \%)$ & 0 & 0 \\
$\mathrm{PR}$ & $5(35.7 \%)$ & $4(33.3 \%)$ & $1(5.6 \%)$ & $3(9.4 \%)$ & $0(0 \%)$ & $12(37.5 \%)$ & $7(53.8 \%)$ \\
$\mathrm{SD}$ & $7(50 \%)$ & $4(33.3 \%)$ & $11(61.1 \%)$ & $19(59.4 \%)$ & $9(75 \%)$ & $16(50 \%)$ & $4(30.8 \%)$ \\
$\mathrm{PD}$ & $2(14.3 \%)$ & $4(33.3 \%)$ & $6(33.3 \%)$ & $9(28.1 \%)$ & $2(16.7 \%)$ & $4(12.5 \%)$ & $2(15.4 \%)$ \\
$\mathrm{N} / \mathrm{A}$ & 0 & 0 & 0 & $1(3.1 \%)$ & 0 & 0 & 0 \\
$\mathrm{CBR} \dagger$ & $85.70 \%$ & $66.60 \%$ & $66.70 \%$ & $68.90 \%$ & $75 \%$ & $87.50 \%$ & $84.60 \%$ \\
$\mathrm{p}$-value (compared with EE) & & 0.53 & 0.11 & 0.15 & 0.09 & $>0.05$ & 0.6 \\
\hline
\end{tabular}

CR denotes complete response, PR denotes partial response, SD denotes stable disease, PD denotes progressive disease, N/A denotes non-available; $\mathrm{p}<0.05$ indicates statistically significant; $\uparrow \mathrm{CBR}$, clinical benefit response $(\mathrm{CR}+\mathrm{PR}+\mathrm{SD})$ 
line treatment for $\mathrm{MBC}$, in accordance with the current recommendation of endocrine therapy in non-visceral crisis population. In BOLERO-2, the protocol had limited the number of prior chemotherapies in advanced disease to $<1$. Therefore, in BOLERO- 2 , only $26 \%$ of patients had received 1 regimen of chemotherapy for metastasis, while in our EE cohort, 28\% (15 patients) and 38\% (20 patients) received one and $>2$ lines of chemotherapy in metastatic setting before receiving EE, respectively.

The optimal timing of $\mathrm{EE}$ in the treatment sequence also remained inconclusive. In BOLERO-2, 74\% received EE immediately after NSAI and hence the recommendation to consider treatment earlier in the course of their disease. However, in our study, only $27 \%$ received $\mathrm{EE}$ as an immediate subsequent therapy after NSAI and $50 \%$ of our patients received EE as their $4^{\text {th }}$ line of treatment. But even with more disease burden and late line use of EE, OS of our cohort compared well to that in BOLERO-2 (BOLERO-2: 31 months (EE) and 27 months (placebo), current study: 33 months (EE) and 25 months (NE)). When considering only 32 patients who received $<1$ line of chemotherapy similar to inclusion criteria of BOLERO-2, OS was 28 months. In BOLERO-6 trial, patients who received everolimus after NSAI failure, OS was only 23 months compared to 25.6 months with capecitabine alone [34]. We found that patients who received EE in later line after NSAI refractory had longer survival (38 months) compared to earlier use although time on treatment was shorter. Because survival in this study was calculated from time of NSAI failure, it is plausible that the patients who received late-line EE were already pre-selected (able to have received several lines of systemic treatment before EE). Other large post-marketing observational studies of everolimus, most of which were also in more heavily pretreated patients similar to ours, could not confirm the adverse effect of prior chemotherapy on outcomes of patients receiving everolimus [32, 36-39]. Moreover, they also demonstrated comparable PFS to BOLERO-2. These data, including ours, thus suggested that EE could be considered at any line of treatment in ER+, HER2 - MBC, with preserved clinical activity.

As stated earlier, the initial unadjusted overall survival was in favor of EE treatment, which could be a result of differences in post-progression therapy. None of the patients in NE group received subsequent everolimus, mainly due to re-imbursement issue. On the contrary, we noted that more patients in EE group also significantly received eribulin compared to NE group. Eribulin has been shown in EMBRACE trial [40] to improve survival compared with physician's treatment choice in patients who had been exposed to multiple systemic therapy. In addition to eribulin use, patients in EE did receive more total lines of systemic treatment than in control arm (5.2 vs 3.6 lines, $\mathrm{p}<0.05)$. When these factors were included into Cox-regression multivariate analysis, numbers of line of treatment was confirmed to be a strong parameter for survival benefit whereas the effect of EE and eribulin use were no longer seen. This finding thus implied that access to multiple treatment lines in MBC is vital for good outcome and everolimus-combination was merely a surrogate marker of access to more sequential treatment, at least in our population with limited healthcare resources. Everolimus/exemestane including CDK4/6 inhibitors and PI3K inhibitors were not included in Thailand's basic cancer protocol of universal coverage health care scheme. Therefore, this finding may have an impact on the policy change to allow access to more lines of therapy that is less costly than EE as currently only 3 lines of chemotherapy are covered for these patients.

Although we have highlighted above some of the interesting observations, this study did have limitations. As might be expected based on a retrospective nature of the non-randomized trial, selection bias was likely to exist. Patients in no-everolimus arm could have been pre-selected not to receive everolimus-exemestane if their disease were rapidly progressing and might result in poorer survival in that arm and thus over-estimated the benefit of everolimus-exemestane. To this aspect, the effect was partially adjusted by Cox-regression analysis. Secondly, our study, compared to other real-world data, was relatively small but yet, with mature data on survival. Thirdly, caution should be noted on PFS and response rate in this study as they were based on local investigator radiographic assessments, which again, could also have been biased. And lastly, our study lacked the information on side effects, dose modification of everolimus and patients' quality of life.

With these limitations in mind, however, we felt that our data provided some valuable perspective for practicing oncologists. In summary, our study based on routine clinical practice, revealed that patients with $\mathrm{HR}+\mathrm{ve}$, HER-2 -ve advanced breast cancer that had progressed on NSAI, the sequential use of multiple treatment options for metastatic breast cancer led to increased survival. Everolimus combined with exemestane could be added into the armamentarium of such treatment with preserved clinical activity in heavily pretreated patients.

\section{Acknowledgements}

The authors would like to thank Ramathibodi Cancer Registry Unit of Ramathibodi Comprehensive Cancer Center for the support of clinical data.

\section{References}

1. Division I, National Cancer Institute T. HOSPITAL BASED CANCER REGISTRY 2015. Pornsup Printing Co., LTD., Bangkok, THAILAND2015. $72 \mathrm{p}$.

2. Morrow M, Burstein H, Harris J. Malignant Tumors of the Breast. In: DeVita VT, Lawrence TS, Rosenberg SA, editors. Cancer Principles \& Practice of Oncology. 10th ed2015.:1117-57.

3. Lim E, Metzger-Filho O, Winer E. The natural history of hormone receptor-positive breast cancer. Oncology (Williston Park). 2012;26(8):688-94.

4. Chung CT, Carlson RW. Goals and Objectives in the Management of Metastatic Breast Cancer. The Oncologist. 2003 Dec;8(6):514-520. https://doi.org/10.1634/ theoncologist.8-6-514

5. Bernard-Marty C, Cardoso F, Piccart MJ. Facts and 
Controversies in Systemic Treatment of Metastatic Breast Cancer. The Oncologist. 2004 Nov;9(6):617-632. https:// doi.org/10.1634/theoncologist.9-6-617

6. Rugo HS, Rumble RB, Macrae E, Barton DL, Connolly HK, Dickler MN, Fallowfield L, Fowble B, Ingle JN, Jahanzeb M, Johnston SR, Korde LA, Khatcheressian JL, Mehta RS, Muss HB, Burstein HJ. Endocrine Therapy for Hormone Receptor-Positive Metastatic Breast Cancer: American Society of Clinical Oncology Guideline. Journal of Clinical Oncology. 201609 01;34(25):3069-3103. https://doi. org/10.1200/jco.2016.67.1487

7. Salkeni M, Hall S. Metastatic breast cancer: Endocrine therapy landscape reshaped. Avicenna Journal of Medicine. 2017;7(4):144. https://doi.org/10.4103/ajm.ajm_20_17

8. Nabholtz J, Buzdar A, Pollak M, Harwin W, Burton G, Mangalik A, Steinberg M, Webster A, von Euler M. Anastrozole Is Superior to Tamoxifen as First-Line Therapy for Advanced Breast Cancer in Postmenopausal Women: Results of a North American Multicenter Randomized Trial. Journal of Clinical Oncology. 2000 Nov 15;18(22):37583767. https://doi.org/10.1200/jco.2000.18.22.3758

9. Bonneterre J, Thürlimann B, Robertson JR, Krzakowski M, Mauriac L, Koralewski P, Vergote I, Webster A, Steinberg M, von Euler M. Anastrozole Versus Tamoxifen as First-Line Therapy for Advanced Breast Cancer in 668 Postmenopausal Women: Results of the Tamoxifen or Arimidex Randomized Group Efficacy and Tolerability Study. Journal of Clinical Oncology. 2000 Nov 15;18(22):3748-3757. https://doi. org/10.1200/jco.2000.18.22.3748

10. Mouridsen H, Gershanovich M, Sun Y, Pérez-Carrión R, Boni C, Monnier A, Apffelstaedt J, Smith R, Sleeboom HP, Jaenicke F, Pluzanska A, Dank M, Becquart D, Bapsy PP, Salminen E, Snyder R, Chaudri-Ross H, Lang R, Wyld P, Bhatnagar A. Phase III Study of Letrozole Versus Tamoxifen as First-Line Therapy of Advanced Breast Cancer in Postmenopausal Women: Analysis of Survival and Update of Efficacy From the International Letrozole Breast Cancer Group. Journal of Clinical Oncology. 200306 01;21(11):2101-2109. https://doi.org/10.1200/ jco.2003.04.194

11. Paridaens RJ, Dirix LY, Beex LV, Nooij M, Cameron DA, Cufer T, Piccart MJ, Bogaerts J, Therasse P. Phase III Study Comparing Exemestane With Tamoxifen As FirstLine Hormonal Treatment of Metastatic Breast Cancer in Postmenopausal Women: The European Organisation for Research and Treatment of Cancer Breast Cancer Cooperative Group. Journal of Clinical Oncology. 2008 Oct 20;26(30):4883-4890. https://doi.org/10.1200/ jco.2007.14.4659

12. Llombart-Cussac A, Ruiz A, Antón A, Barnadas A, Antolín S, Alés-Martínez JE, Álvarez I, Andrés R, García Saenz JA, Lao J, Carrasco E, Cámara C, Casas I, Martín M. Exemestane versus anastrozole as front-line endocrine therapy in postmenopausal patients with hormone receptor-positive, advanced breast cancer. Cancer. 201106 29;118(1):241-247. https://doi.org/10.1002/cncr.26299

13. Iwata H, Masuda N, Ohno S, Rai Y, Sato Y, Ohsumi S, Hashigaki S, Nishizawa Y, Hiraoka M, Morimoto T, Sasano H, Saeki T, Noguchi S. A randomized, double-blind, controlled study of exemestane versus anastrozole for the first-line treatment of postmenopausal Japanese women with hormone-receptor-positive advanced breast cancer. Breast Cancer Research and Treatment. 2013 05 30;139(2):441-451. https://doi.org/10.1007/s10549-013-2573-3

14. Finn RS, Martin M, Rugo HS, Jones S, Im S, Gelmon K, Harbeck N, Lipatov ON, Walshe JM, Moulder S, Gauthier E,
Lu DR, Randolph S, Diéras V, Slamon DJ. Palbociclib and Letrozole in Advanced Breast Cancer. New England Journal of Medicine. 2016 Nov 17;375(20):1925-1936. https://doi. org/10.1056/nejmoa1607303

15. Turner NC, Slamon DJ, Ro J, Bondarenko I, Im S, Masuda N, Colleoni M, DeMichele A, Loi S, Verma S, Iwata H, Harbeck N, Loibl S, André F, Puyana Theall K, Huang X, Giorgetti C, Huang Bartlett C, Cristofanilli M. Overall Survival with Palbociclib and Fulvestrant in Advanced Breast Cancer. New England Journal of Medicine. 2018 Nov 15;379(20):19261936. https://doi.org/10.1056/nejmoa1810527

16. Hortobagyi GN, Stemmer SM, Burris HA, Yap Y, Sonke GS, Paluch-Shimon S, Campone M, Blackwell KL, André F, Winer EP, Janni W, Verma S, Conte P, Arteaga CL, Cameron DA, Petrakova K, Hart LL, Villanueva C, Chan A, Jakobsen E, Nusch A, Burdaeva O, Grischke E, Alba E, Wist E, Marschner N, Favret AM, Yardley D, Bachelot T, Tseng L, Blau S, Xuan F, Souami F, Miller M, Germa C, Hirawat S, O'Shaughnessy J. Ribociclib as First-Line Therapy for HR-Positive, Advanced Breast Cancer. New England Journal of Medicine. 2016 Nov 03;375(18):1738-1748. https://doi. org/10.1056/nejmoa1609709

17. Slamon DJ, Neven P, Chia S, Fasching PA, De Laurentiis M, Im S, Petrakova K, Bianchi GV, Esteva FJ, Martín M, Nusch A, Sonke GS, De la Cruz-Merino L, Beck JT, Pivot X, Vidam G, Wang Y, Rodriguez Lorenc K, Miller M, Taran T, Jerusalem G. Phase III Randomized Study of Ribociclib and Fulvestrant in Hormone Receptor-Positive, Human Epidermal Growth Factor Receptor 2-Negative Advanced Breast Cancer: MONALEESA-3. Journal of Clinical Oncology. 201808 20;36(24):2465-2472. https:// doi.org/10.1200/jco.2018.78.9909

18. Goetz MP, Toi M, Campone M, Sohn J, Paluch-Shimon S, Huober J, Park IH, Trédan O, Chen S, Manso L, Freedman OC, Garnica Jaliffe G, Forrester T, Frenzel M, Barriga S, Smith IC, Bourayou N, Di Leo A. MONARCH 3: Abemaciclib As Initial Therapy for Advanced Breast Cancer. Journal of Clinical Oncology. 2017 Nov 10;35(32):36383646. https://doi.org/10.1200/jco.2017.75.6155

19. Sledge GW, Toi M, Neven P, Sohn J, Inoue K, Pivot X, Burdaeva O, Okera M, Masuda N, Kaufman PA, Koh H, Grischke E, Frenzel M, Lin Y, Barriga S, Smith IC, Bourayou N, Llombart-Cussac A. MONARCH 2: Abemaciclib in Combination With Fulvestrant in Women With HR+/HER2Advanced Breast Cancer Who Had Progressed While Receiving Endocrine Therapy. Journal of Clinical Oncology. 201709 01;35(25):2875-2884. https://doi.org/10.1200/ jco.2017.73.7585

20. Buzdar A, Jonat W, Howell A, Jones S, Blomqvist C, Vogel $\mathrm{C}$, et al. Anastrozole versus megestrol acetate in the treatment of postmenopausal women with advanced breast carcinoma: results of a survival update based on a combined analysis of data from two mature phase III trials. Arimidex Study Group. Cancer. 1998;83(6):1142-52.

21. Dombernowsky P, Smith I, Falkson G, Leonard R, Panasci L, Bellmunt J, Bezwoda W, Gardin G, Gudgeon A, Morgan M, Fornasiero A, Hoffmann W, Michel J, Hatschek T, Tjabbes T, Chaudri HA, Hornberger U, Trunet PF. Letrozole, a new oral aromatase inhibitor for advanced breast cancer: double-blind randomized trial showing a dose effect and improved efficacy and tolerability compared with megestrol acetate.. Journal of Clinical Oncology. 1998 02;16(2):453-461. https://doi. org/10.1200/jco.1998.16.2.453

22. Di Leo A, Jerusalem G, Petruzelka L, Torres R, Bondarenko IN, Khasanov R, Verhoeven D, Pedrini JL, Smirnova I, Lichinitser MR, Pendergrass K, Garnett S, Lindemann JP, 
Sapunar F, Martin M. Results of the CONFIRM Phase III Trial Comparing Fulvestrant $250 \mathrm{mg}$ With Fulvestrant 500 mg in Postmenopausal Women With Estrogen ReceptorPositive Advanced Breast Cancer. Journal of Clinical Oncology. 2010 Oct 20;28(30):4594-4600. https://doi. org/10.1200/jco.2010.28.8415

23. Chia S, Gradishar W, Mauriac L, Bines J, Amant F, Federico M, Fein L, Romieu G, Buzdar A, Robertson JF, Brufsky A, Possinger K, Rennie P, Sapunar F, Lowe E, Piccart M. Double-Blind, Randomized Placebo Controlled Trial of Fulvestrant Compared With Exemestane After Prior Nonsteroidal Aromatase Inhibitor Therapy in Postmenopausal Women With Hormone Receptor-Positive, Advanced Breast Cancer: Results From EFECT. Journal of Clinical Oncology. 200804 01;26(10):1664-1670. https:// doi.org/10.1200/jco.2007.13.5822

24. Efeyan A, Sabatini DM. mTOR and cancer: many loops in one pathway. Current Opinion in Cell Biology. 2010 04;22(2):169-176. https://doi.org/10.1016/j.ceb.2009.10.007

25. Johnston SR. Clinical Efforts to Combine Endocrine Agents with Targeted Therapies against Epidermal Growth Factor Receptor/Human Epidermal Growth Factor Receptor 2 and Mammalian Target of Rapamycin in Breast Cancer. Clinical Cancer Research. 200602 01;12(3):1061s-1068s. https://doi. org/10.1158/1078-0432.ccr-05-2125

26. Burstein HJ. NovelAgents and Future Directions for Refractory Breast Cancer. Seminars in Oncology. 2011 06;38:S17-S24. https://doi.org/10.1053/j.seminoncol.2011.04.002

27. . Comprehensive molecular portraits of human breast tumours. Nature. 201209 23;490(7418):61-70. https://doi. org/10.1038/nature 11412

28. Ellis MJ, Ding L, Shen D, Luo J, Suman VJ, Wallis JW, et al. Whole-genome analysis informs breast cancer response to aromatase inhibition. Nature. 2012 06;486(7403):353-360. https://doi.org/10.1038/nature11143

29. Bachelot T, Bourgier C, Cropet C, Ray-Coquard I, Ferrero J, Freyer G, Abadie-Lacourtoisie S, Eymard J, Debled M, Spaëth D, Legouffe E, Allouache D, El Kouri C, PujadeLauraine E. Randomized Phase II Trial of Everolimus in Combination With Tamoxifen in Patients With Hormone Receptor-Positive, Human Epidermal Growth Factor Receptor 2-Negative Metastatic Breast Cancer With Prior Exposure to Aromatase Inhibitors: A GINECO Study. Journal of Clinical Oncology. 201208 01;30(22):2718-2724. https://doi.org/10.1200/jco.2011.39.0708

30. Baselga J, Campone M, Piccart M, Burris HA, Rugo HS, Sahmoud T, Noguchi S, Gnant M, Pritchard KI, Lebrun F, Beck JT, Ito Y, Yardley D, Deleu I, Perez A, Bachelot T, Vittori L, Xu Z, Mukhopadhyay P, Lebwohl D, Hortobagyi GN. Everolimus in Postmenopausal Hormone-ReceptorPositive Advanced Breast Cancer. New England Journal of Medicine. 201202 09;366(6):520-529. https://doi. org/10.1056/nejmoa1109653

31. Yardley DA, Noguchi S, Pritchard KI, Burris HA, Baselga J, Gnant M, Hortobagyi GN, Campone M, Pistilli B, Piccart M, Melichar B, Petrakova K, Arena FP, Erdkamp F, Harb WA, Feng W, Cahana A, Taran T, Lebwohl D, Rugo HS. Everolimus Plus Exemestane in Postmenopausal Patients with HR+ Breast Cancer: BOLERO-2 Final ProgressionFree Survival Analysis. Advances in Therapy. 2013 Oct;30(10):870-884. https://doi.org/10.1007/s12325-0130060-1

32. Piccart M, Hortobagyi G, Campone M, Pritchard K, Lebrun F, Ito Y, et al. Everolimus plus exemestane for hormone-receptor-positive, human epidermal growth factor receptor-2-negative advanced breast cancer: overall survival results from BOLERO-2. Annals of Oncology. 2014 Dec;25(12):2357-2362. https://doi.org/10.1093/annonc/ mdu456

33. Noguchi S, Masuda N, Iwata H, Mukai H, Horiguchi J, Puttawibul P, Srimuninnimit V, Tokuda Y, Kuroi K, Iwase H, Inaji H, Ohsumi S, Noh W, Nakayama T, Ohno S, Rai Y, Park B, Panneerselvam A, El-Hashimy M, Taran T, Sahmoud T, Ito Y. Efficacy of everolimus with exemestane versus exemestane alone in Asian patients with HER2-negative, hormone-receptor-positive breast cancer in BOLERO-2. Breast Cancer. 201302 13;21(6):703-714. https://doi. org/10.1007/s12282-013-0444-8

34. Jerusalem G, de Boer RH, Hurvitz S, Yardley DA, Kovalenko E, Ejlertsen B, et al. Everolimus Plus Exemestane vs Everolimus or Capecitabine Monotherapy for Estrogen Receptor-Positive, HER2-Negative Advanced Breast Cancer. JAMA Oncology. 2018 Oct 01;4(10):1367. https:// doi.org/10.1001/jamaoncol.2018.2262

35. Riccardi F, Colantuoni G, Diana A, Mocerino C, Carten $\square$ G, Lauria R, Febbraro A, Nuzzo F, Addeo R, Marano O, Incoronato P, De Placido S, Ciardiello F, Orditura M. Exemestane and Everolimus combination treatment of hormone receptor positive, HER2 negative metastatic breast cancer: A retrospective study of 9 cancer centers in the Campania Region (Southern Italy) focused on activity, efficacy and safety. Molecular and Clinical Oncology. 2018 07 16; https://doi.org/10.3892/mco.2018.1672

36. Ciruelos E, Vidal M, Martínez de Dueñas E, Martínez-Jáñez N, Fernández Y, García-Sáenz JA, Murillo L, Carabantes F, Beliera A, Fonseca R, Gavilá J. Safety of everolimus plus exemestane in patients with hormone-receptor-positive, HER2-negative locally advanced or metastatic breast cancer: results of phase IIIb BALLET trial in Spain. Clinical and Translational Oncology. 2017 Nov 07;20(6):753-760. https:// doi.org/10.1007/s12094-017-1784-1

37. Tesch H, Stoetzer O, Decker T, Kurbacher CM, Marmé F, Schneeweiss A, et al. Efficacy and safety of everolimus plus exemestane in postmenopausal women with hormone receptor-positive, human epidermal growth factor receptor 2-negative locally advanced or metastatic breast cancer: Results of the single-arm, phase IIIB 4EVER trial. International Journal of Cancer. 2018 Oct 30;144(4):877885. https://doi.org/10.1002/ijc.31738

38. Lousberg L, Jerusalem G. Safety, Efficacy, and Patient Acceptability of Everolimus in the Treatment of Breast Cancer. Breast Cancer: Basic and Clinical Research. 2016 01;10:BCBCR.S12443. https://doi.org/10.4137/bcbcr. s 12443

39. Moscetti L, Vici P, Gamucci T, Natoli C, Cortesi E, Marchetti $\mathrm{P}$, et al. Safety analysis, association with response and previous treatments of everolimus and exemestane in 181 metastatic breast cancer patients: A multicenter Italian experience. The Breast. 2016 Oct;29:96-101. https://doi. org/10.1016/j.breast.2016.07.005

40. Cortes J, O'Shaughnessy J, Loesch D, Blum JL, Vahdat LT, Petrakova K, et al. Eribulin monotherapy versus treatment of physician's choice in patients with metastatic breast cancer (EMBRACE): a phase 3 open-label randomised study. The Lancet. 2011 03;377(9769):914-923. https://doi. org/10.1016/s0140-6736(11)60070-6

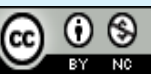

This work is licensed under a Creative Commons AttributionNon Commercial 4.0 International License. 